\title{
First Reproductive Observations for Herpele Peters, 1880 (Amphibia: Gymnophiona: Herpelidae): Evidence of Extended Parental Care and Maternal Dermatophagy in H. squalostoma (Stutchbury, 1836)
}

\author{
Marcel T. Kouete, ${ }^{1,2}$ Mark Wilkinson, ${ }^{3}$ and David J. Gower ${ }^{3}$ \\ ${ }^{1}$ Project Cameroon Herpetology, Conservation Biology Foundation, Yaoundé, Cameroon \\ ${ }^{2}$ Zoological Society of London, London NW1 4RY, UK \\ ${ }^{3}$ Department of Life Sciences, The Natural History Museum, London SW7 5BD, UK
}

Correspondence should be addressed to David J. Gower, d.gower@nhm.ac.uk

Received 25 September 2012; Accepted 18 October 2012

Academic Editors: A. Arslan and B. A. Young

Copyright ( $) 2012$ Marcel T. Kouete et al. This is an open access article distributed under the Creative Commons Attribution License, which permits unrestricted use, distribution, and reproduction in any medium, provided the original work is properly cited.

\begin{abstract}
An adult (presumably female) Herpele squalostoma was found attending 16 young in Cameroon. Four young that were preserved one day after collection have multicusped teeth and skin-like material in their gut. The adult and remaining young were maintained in captivity without provision of food for one month. During this period the young gained more than $10 \%$ in mass. Twenty-nine days after collection one additional young was preserved, this has adult-like dentition. We conclude that H. squalostoma resembles the oviparous caecilians Boulengerula taitanus and Siphonops annulatus in having young that receive extended parental care and that remove and eat the stratum corneum of maternal skin using specialized deciduous teeth. This discovery matches a prediction that maternal dermatophagy is widespread (and homologous) among teresomatan caecilians.
\end{abstract}

\section{Introduction}

The reproductive biology of caecilian amphibians (Gymnophiona) is remarkably diverse for a clade of fewer than 200 extant nominal species. In addition to both oviparity (with larvae or direct development) and viviparity, there is a range of types and duration of parental care, some of which have been only recently discovered [1-4]. Establishing evolutionary patterns in the reproductive biology of caecilians has been challenging because little to no information is available for most species and some genera $[5,6]$.

Kupfer et al. [3] described a form of parental care in the oviparous, direct-developing, East African, herpelid caecilian Boulengerula taitanus. In this species, altricial hatchlings periodically remove and ingest the outer layer (stratum corneum) of hypertrophied skin of attending females using distinctive multicusped teeth that are shed when the young assume an independent existence. Wilkinson et al. [7] reported this maternal dermatophagy in another oviparous, direct-developing caecilian, the South American siphonopid Siphonops annulatus. Based on the similarity of the syndrome of morphological and behavioural traits characterizing the maternal dermatophagy, Wilkinson et al. [7] hypothesized that it is homologous in the two species and predicted that skin feeding also occurs in many oviparous, directdeveloping teresomatan [8] caecilians. Here we provide the first report of reproductive natural history data for the central African herpelid genus Herpele. An adult $H$. squalostoma was found attending a clutch of young. Study of this clutch and data from independent $H$. squalostoma suggest that this species is oviparous and also has maternal dermatophagy.

\section{Materials and Methods}

The newly discovered adult and clutch were found by MTK by digging with a hoe on 26 June 2012 during 

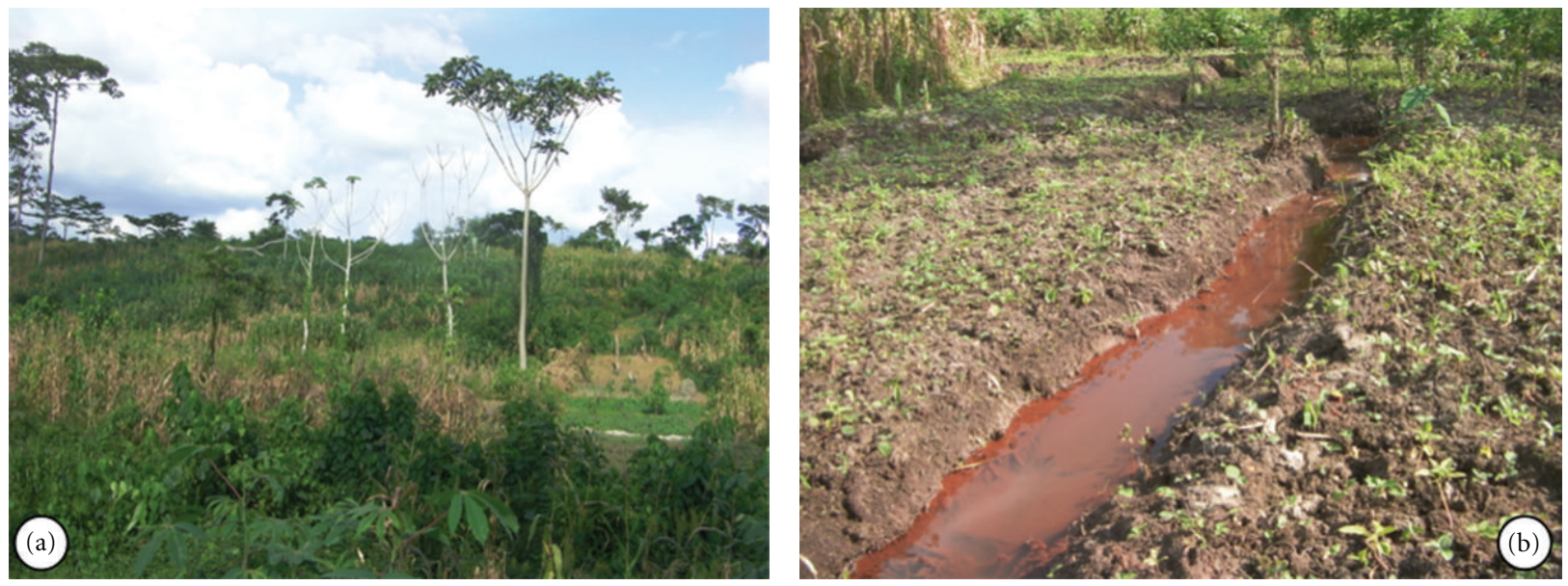

Figure 1: Photographs (taken by MTK) of the locality where the Herpele squalostoma clutch was found. (a) general setting, (b) one of the drainage canals crossing the agricultural plots.

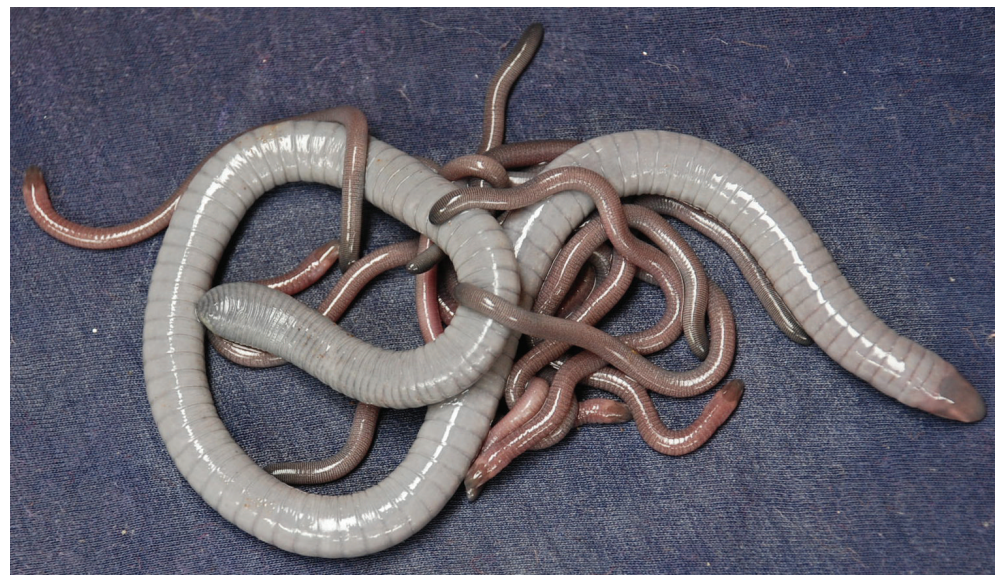

Figure 2: Clutch of Herpele squalostoma in life on day of field collection (June 26, 2012). Adult total length approximately $36 \mathrm{~cm}$. Photograph by MTK.

a dedicated search for caecilians. The locality $\left(3^{\circ} 53.814^{\prime} \mathrm{N}\right.$, $11^{\circ} 35.433^{\prime} \mathrm{E}, 688 \mathrm{~m}$ above sea level) is at Nkong on the northeastern outskirts of the city of Yaoundé, Centre Region, Cameroon. The site (Figure 1) is in an area (approximately $25 \mathrm{~m} \times 125+\mathrm{m}$ ) of lower-lying land traversed by narrow drainage canals. Secondary forest has been cleared by slash and burn here and the place where the clutch was found has been under agriculture (including maize and cocoyam) for the past four years according to local farmers.

The live mother and young (Figure 2) were stored together in a bag of soil from the collection site. Within one day, the caecilians and soil were transferred to a plastic box and kept at ambient conditions in Yaoundé, indoors and in the shade. After one day, the clutch was moved into a plastic box containing moist paper towel but no soil. Fifteen days after collection, the clutch was transferred by air to London, UK and moved into a fresh box of moist paper towel and maintained at approximately $25^{\circ} \mathrm{C}$ on a $12-12$ hour inverse light cycle. Periodically, the adult and young were weighed (to $0.01 \mathrm{~g}$ ), generally individually but on two occasions, the young were weighed together to reduce disturbance. The containers were kept moist but no food was given to the caecilians between their collection in the field and 40 days after collection, at which point they were transferred to a box of sterilized topsoil and provided ad libitum with live oligochaete worms (earthworms and white worms).

One day after collection four young were removed permanently from the clutch. They were anaesthetized in an aqueous solution of MS222 (Sandoz), weighed, measured (to $1 \mathrm{~mm}$; total length, TL by gently stretching along a ruler), fixed in ca. $4 \%$ aqueous formaldehyde for 48 hours, washed thoroughly in water and stored in $70 \%$ ethanol. These four young included the approximately largest and smallest individuals as judged by eye. Twenty-nine days after collection one of the smallest remaining young was permanently removed, weighed, measured, and preserved as described above. Specimens were examined with a dissecting light microscope. Mandibular musculature was examined 
TABle 1: Meristic and morphometric (in $\mathrm{mm}$ ) data for five preserved young Herpele squalostoma from a clutch of 16 young attended by an adult. All specimens have NHMUK prefix. The specimens in the first four rows were preserved one day after field collection and all have multicusped teeth. The specimen in the bottom row was preserved 29 days after collection and has adult-like dentition. Abbreviations: TL (a): total length fresh on day of preservation; TL (b): total length in preservation; MbW: width at midbody; HL: head length measured laterally from snout tip to first collar groove; HW: maximum head width between corner of mouth and first collar groove; PAs: total number of primary annuli; 1st SAG, primary annulus on which anteriormost secondary annular groove occurs; +: plus a small terminal cap substantially shorter than preceding primary annulus.

\begin{tabular}{lccccccc}
\hline Specimen & TL $(\mathrm{a})$ & TL $(\mathrm{b})$ & MbW & HL & HW & PAs & 1 1st SAG \\
\hline 2012.1 & 112 & 111 & 3.2 & 5.4 & 3.7 & 4.1 & $116+$ \\
2012.2 & 117 & 112 & 3.6 & 5.6 & 5.4 & 98 & $119+$ \\
2012.3 & 114 & 113 & 3.2 & 3.6 & 5.7 & 9.1 & 117 \\
2012.4 & 122 & 120 & 3.3 & 5.5 & 3.9 & 99 \\
2012.5 & 120 & 114 & & & 96 \\
\hline
\end{tabular}

by superficial dissection of one specimen. Comparisons were made with data from a sample of 122 additional Herpele squalostoma in the collections of the Natural History Museum, London, UK (BMNH and NHMUK prefixes) and the Royal Museum for Central Africa, Tervuren, Belgium. Classification follows Wilkinson et al. [9] and Kamei et al. [10].

\section{Results}

The clutch was found approximately $0.3 \mathrm{~m}$ from the edge of a drainage canal that held a small amount of stagnant water, and under canopy cover of less than 20\% (estimated by eye over an area of $6 \mathrm{~m} \times 6 \mathrm{~m}$ ) provided by sparse trees. The clutch was dug from silty-clay soil (assessed with the hand method of Dubbin [11]) at a depth of approximately $0.1 \mathrm{~m}$ below the surface, which had a cover of grasses and other low herbaceous vegetation. The soil was not dug particularly carefully and the clutch find was unexpected, and no chamber-like structure or soil heterogeneity was noticed when the clutch was removed. The soil in the vicinity of the clutch retained moisture but was not wet. The young in the clutch were capable of burrowing in loose soil unassisted.

The caecilians are identified as Herpele Peters, 1880 because this is the only African caecilian genus with both secondary annular grooves and eyes that are covered with bone and not visible externally. They are identified as $H$. squalostoma (Stutchbury, 1859) on the basis of having fewer than 135 primary annuli [12]. The five preserved young have 116-119 primary annuli (Table 1), and from a photograph (Figure 2), the mother has ca. 117. These numbers lie within but close to the lower limit of numbers of annuli (116-132, $\bar{x}=122 \pm 2.64)$ in a sample of $122 \mathrm{H}$. squalostoma. The anteriormost secondary annular groove of the young occurs on the 96-99th primary annulus (Table 1), corresponding to between 19 and 23 secondary annular grooves, well within the range $(15-45, \bar{x}=26.57 \pm 7.74)$ observed for the species.

The adult, a fairly typical example of $H$. squalostoma, was approximately $363 \mathrm{~mm}$ TL measured alive on 02 September 2012. The masses and some dimensions of the young are presented in Table 2, with masses also shown graphically in Figure 3 . The total mass of the 12 young surviving after day 1 (and of the heaviest and lightest examples alone) increased by more than $10 \%$ between days 4 and 28 . The adult decreased in mass by more than $10 \%$ from day 1 to 28 ( $8 \%$ from day 4 to 28 ) but there was a substantial decrease by days 10 and 13 and similar increase in mass by day 15 . At day 28 , the 12 surviving young were each $4.3-6.5 \%$ of the mass of the adult.

The four young preserved one day after collection (NHMUK 2012.1-4; Figures 4 and 5) superficially resemble adult $H$. squalostoma in that the body is pigmented, the eye is not visible, the tentacle is far in front of the expected position of the eye and closer to the nostril, and the annular grooves are clearly demarcated. Scales are also present, a small (subcircular, ca. $0.15 \mathrm{~mm}$ wide) example was removed from the middorsal part of an annular fold at the 107th primary annulus. External bulges caused by the underlying $m$. depressor mandibulae and $m$. interhyoideus posterior are more prominent than in adults but there is nothing atypical about the mandibular musculature. The most noteworthy difference from adult morphology is seen in the dentition. Whereas adults have pointed, monocusped teeth in single rows, the outer teeth in the lower jaw of the young are distinctly multicusped with transversely expanded (not pointed) tips and occur in perhaps three irregular rows. Some of these multicusped teeth are long and recurved and extend far clear of the gingivae. The teeth in the upper jaw of the four young are less numerous and do not occur in as many rows. They are also less prominent relative to the gingivae, and some monocusped elements might be present, but some multicusped teeth occur on at least the premaxilla and vomer of NHMUK 2012.3. The gut of one specimen (NHMUK 2012.4) was opened halfway along the body and the contents removed (Figure 4(c)). These include a few inorganic particles but are dominated by a highly folded, very thin, and transparent sheet, consistent with the animal having ingested stratum corneum.

The single young specimen preserved 29 days after collection (NHMUK 2012.5; Figures 4 and 5) is no larger than the four young preserved 28 days earlier and does not differ notably in pigmentation, position of the tentacle, or distinctiveness of annular grooves. The external bulges of the $m$. depressor mandibulae and $m$. interhyoideus posterior are less prominent than in the young preserved one day after collection. The teeth are adult-like in being arranged in single inner and outer rows in both the upper and lower 
TABLE 2: Changes in mass (in g) during one month for a clutch of 16 young and one attending adult Herpele squalostoma discovered on June 26,2012 . Animals were weighed to $0.01 \mathrm{~g}$, but mass is here given to a precision of $0.1 \mathrm{~g}$. Young $13-16$ were removed permanently on day 1 . The young were not individually marked such that individual changes in mass were not recorded, young are instead listed in decreasing order of mass for each date weighed.

\begin{tabular}{|c|c|c|c|c|c|c|c|c|}
\hline & \multicolumn{8}{|c|}{ Date (days since collection in field) } \\
\hline & 27 June (1) & 30 June (4) & 6 July (10) & 9 July (13) & 11 July (15) & 14 July (18) & 18 July (22) & 24 July (28) \\
\hline Adult & 26.2 & 25.3 & 22.8 & 22.8 & 24.6 & 24.7 & 24.7 & 23.1 \\
\hline Total 12 young & & 12.8 & 13.3 & 14.0 & 13.9 & 14.5 & 13.9 & 14.4 \\
\hline Young 1 & & 1.3 & 1.3 & & & 1.4 & 1.4 & 1.5 \\
\hline Young 2 & & 1.2 & 1.3 & & & 1.4 & 1.3 & 1.5 \\
\hline Young 3 & & 1.1 & 1.3 & & & 1.3 & 1.3 & 1.3 \\
\hline Young 4 & & 1.1 & 1.1 & & & 1.3 & 1.2 & 1.3 \\
\hline Young 5 & & 1.1 & 1.1 & & & 1.2 & 1.2 & 1.3 \\
\hline Young 6 & & 1.1 & 1.1 & & & 1.2 & 1.2 & 1.2 \\
\hline Young 7 & & 1.1 & 1.1 & & & 1.2 & 1.1 & 1.1 \\
\hline Young 8 & & 1.0 & 1.1 & & & 1.2 & 1.1 & 1.1 \\
\hline Young 9 & & 1.0 & 1.0 & & & 1.1 & 1.1 & 1.1 \\
\hline Young 10 & & 1.0 & 1.0 & & & 1.1 & 1.0 & 1.0 \\
\hline Young 11 & & 0.9 & 1.0 & & & 1.1 & 1.0 & 1.0 \\
\hline Young 12 & & 0.9 & 0.9 & & & 1.0 & 1.0 & 1.0 \\
\hline Young 13 & 1.2 & & & & & & & \\
\hline Young 14 & 1.1 & & & & & & & \\
\hline Young 15 & 1.0 & & & & & & & \\
\hline Young 16 & 1.0 & & & & & & & \\
\hline
\end{tabular}

jaw, and being monocusped, at least in the outer rows where they are most readily examined. The gingivae of this specimen are somewhat swollen but there are approximately 25 premaxillary-maxillary and 18 to 20 dentary teeth.

\section{Discussion}

Wilkinson and Nussbaum [5] mentioned three lines of indirect evidence of oviparity in caecilians, namely large oviductal eggs, larval characteristics in young specimens, and extrapolation from knowledge of close relatives. In the absence of such evidence, they listed the reproductive mode of Herpele as unknown. The young $H$. squalostoma reported here lack larval features and the species presumably also lacks a larval stage. The largest oviductal eggs we have seen in adult $H$. squalostoma measure $3.5 \times 2.6 \mathrm{~mm}$ and are not smaller than those reported for the oviparous Gegeneophis ramaswami [1]. Nothing is known about reproduction in $H$. multiplicata, the only congener and presumed closest relative of $H$. squalostoma but, as far as is known, other members of the Herpelidae and of its sister group the Chikilidae are oviparous $[10,13]$. An additional line of evidence that $H$. squalostoma is not viviparous is that embryos or foetuses have not been found despite there being fairly good samples of this species in scientific collections with many adult female $H$. squalostoma having been X-rayed and/or had their coeloms opened to determine sex (DJG, MW, unpublished data). Taken together this evidence makes it most plausible that H. squalostoma is oviparous.
The presence of a deciduous, multicusped, and polystichous juvenile dentition in young Boulengerula taitanus and Siphonops annulatus was one of the key observations leading to the discovery of maternal dermatophagy in these species $[3,7,14]$. The presence of a similar dentition in young $H$. squalostoma that were found in association with an attending adult is thus good evidence that this species is similarly dermatophagous. The recorded increase in mass of young $H$. squalostoma during one month without provision of any other food is consistent with the interpretation that they were feeding on the skin of the attending adult during that period. This inference is supported further by sheets of skin-like material in the gut of the young that are likely too large to be from any of the young themselves. In addition, the proportionately large jaw muscles in these young might be expected of animals that are rasping and peeling skin, and similarly large muscles are seen also in, for example, skin-feeding $S$. annulatus [7, Figure 1(c)]. No bouts of $H$. squalostoma skin feeding were observed but the clutch was not disturbed or examined very often, and bouts of skin feeding observed in other caecilian mothers are brief and can be interspersed with long periods of nonfeeding [7]. The fluctuations of the mass of the adult are difficult to explain on the basis of a single clutch, with possible post hoc explanations including fluctuations caused by changes in water content as it was moved from the field to Yaoundé and then to London. The adult is presumably the mother of the clutch, but it is still alive at the time of writing, and we have no direct evidence yet that it is female. 


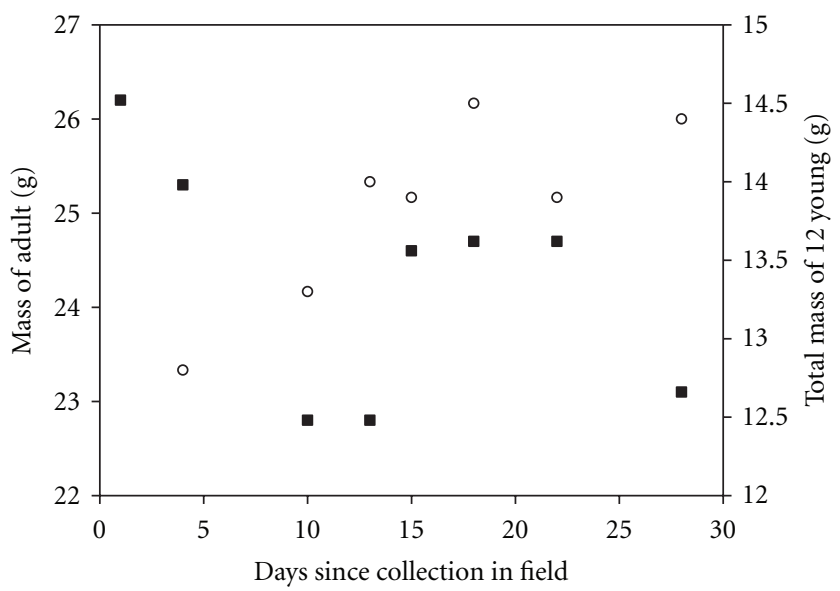

Figure 3: Graph of mass through time of 12 of the young Herpele squalostoma (empty circles) and the attending adult (filled squares).

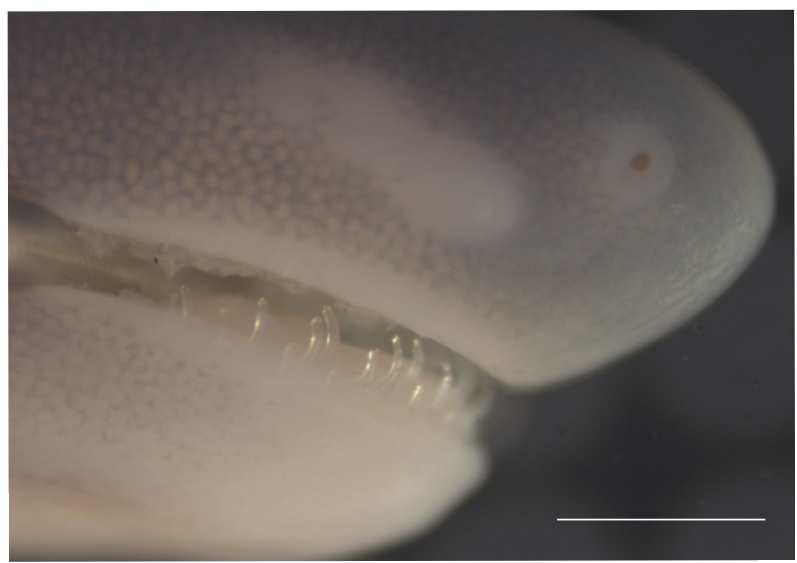

(a)

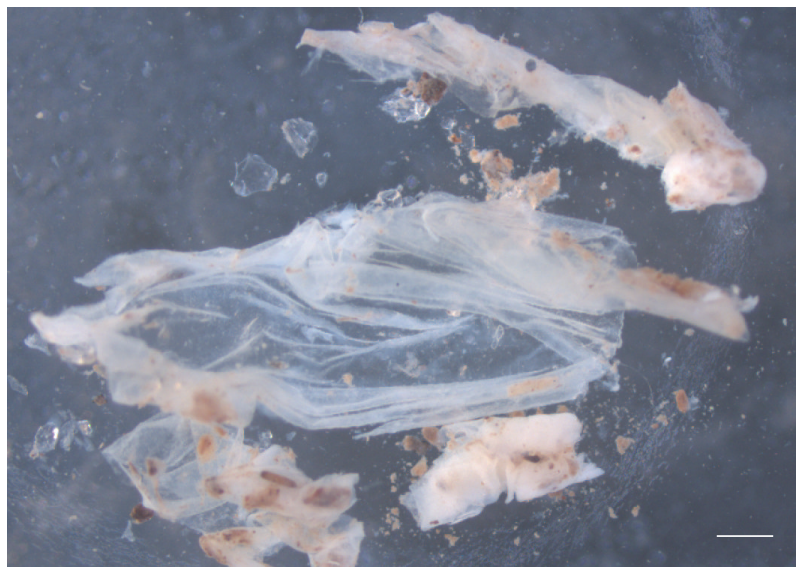

(c)

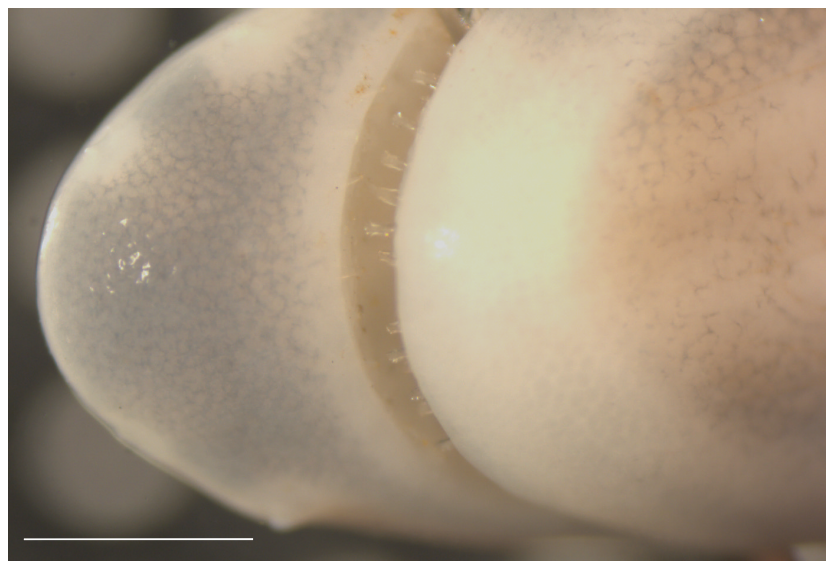

(b)

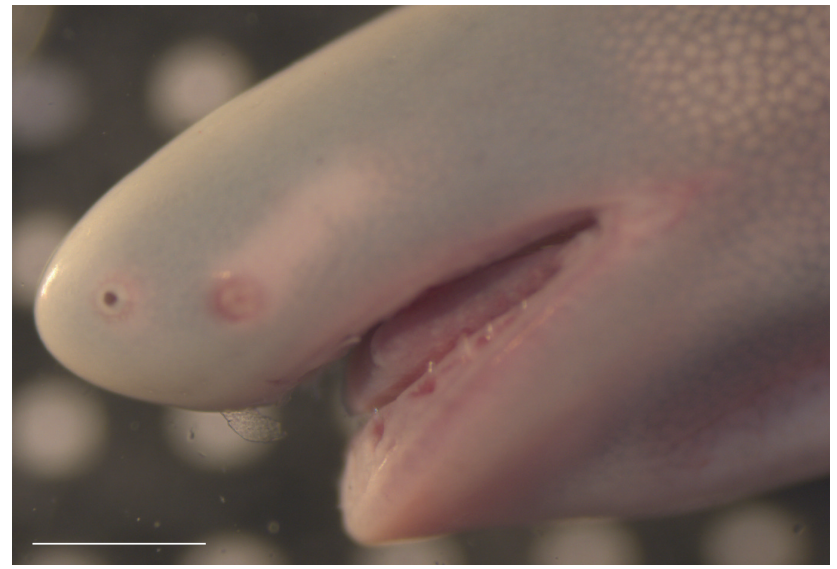

(d)

FiguRe 4: Young Herpele squalostoma. (a) right lateral and (b) ventral view of anterior of mouth showing multicusped teeth of young (NHMUK 2012.2) preserved one day after field collection of clutch; (c) gut contents of young (NHMUK 2012.4) preserved one day after field collection of clutch; (d) left lateral view of mouth showing adult-like dentition of young (NHMUK 2012.5) preserved 29 days after field collection of clutch. Scale bars $1 \mathrm{~mm}$. Photographs by DJG. 


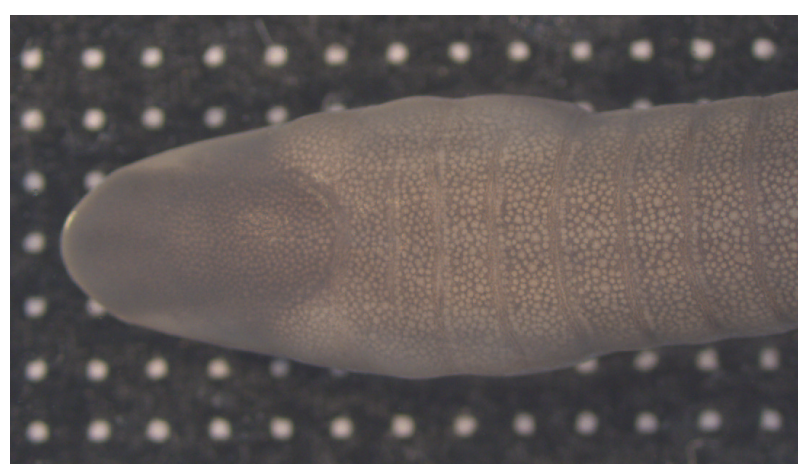

(a)

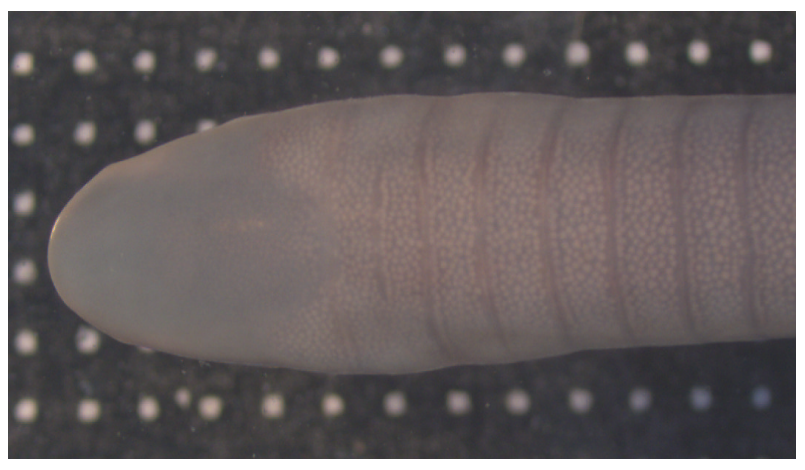

(c)

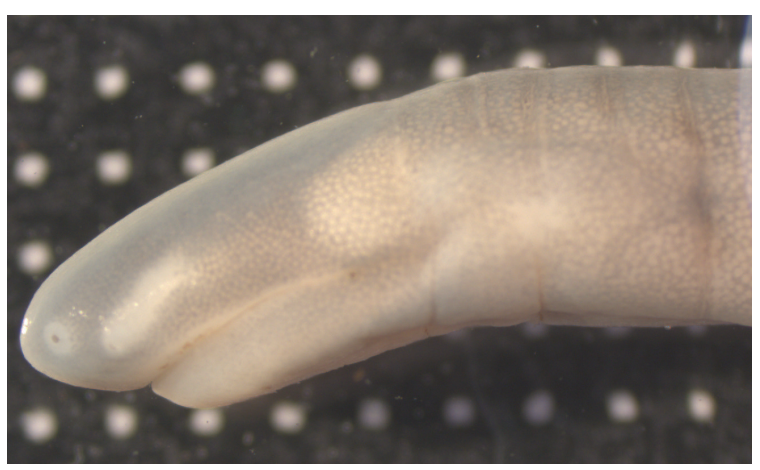

(b)

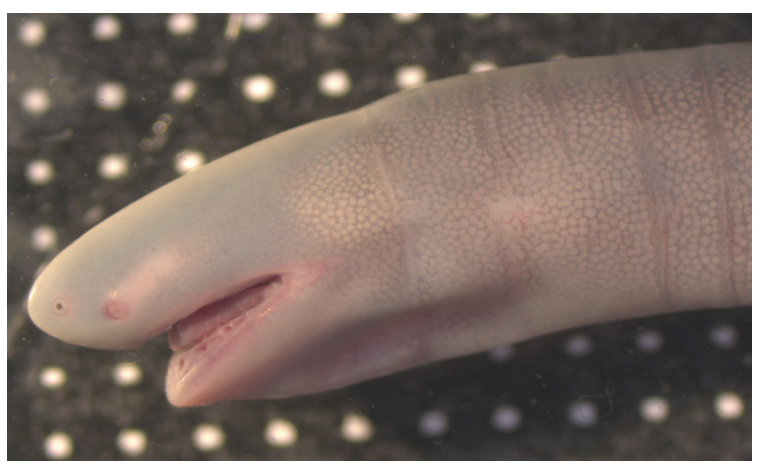

(d)

Figure 5: Head and collar region of young Herpele squalostoma. (a) Dorsal view of NHMUK 2012.4; (b) left lateral view of NHMUK 2012.2; (c) dorsal (d) left lateral views of NHMUK 2012.5. Specimens preserved 1 day (NHMUK 2012.2, 2012.4) and 29 days (NHMUK 2012.5) after field collection of clutch. Pale dots in background are $1 \mathrm{~mm}$ apart. Photographs by DJG.

The young $H$. squalostoma were already well developed when the clutch was discovered and lost their deciduous multicusped dentition within one month in captivity at a length of approximately $120 \mathrm{~mm}$ and mass of a little over $1 \mathrm{~g}$. We suspect that when they were captured they had been hatched for a considerable time and suggest that weight gain (and maternal weight loss) would have been more noticeable earlier in development. Weight loss has been documented in nursing mothers of B. taitanus $[3,14]$. Caecilian mothers providing hypertrophied skin to young have been observed to change colour, becoming paler and somewhat "milky" in appearance in both $B$. taitanus and S. annulatus $[3,7]$. The adult $H$. squalostoma attending the clutch was not notably different in colour to other adults of this species that we have collected in Cameroon, but the species' "normal" grey colour (at least in Cameroon, personal observation) would presumably make this less obvious than in the typical blueish colour of the other two taxa. The smallest independent $H$. squalostoma from Cameroon in our sample are $108-132 \mathrm{~mm}$ TL (BMNH 2008.324, 350, 617 and 621) and all have typical adult dentition, providing further evidence that young $H$. squalostoma gain their adult dentition (and likely become independent) at a TL of approximately $100-120 \mathrm{~mm}$.

Based on similarities with Boulengerula and Siphonops, we expect hatchling $H$. squalostoma to be altricial and much less pigmented than the young reported here. Most of the annual precipitation in Yaoundé falls between March and
November with two peak periods, a longer, less pronounced one from March to June and a shorter more pronounced one from September to November. A single datum is a weak basis for interpretation, but the newly discovered clutch was coincident with the first of the two rainy periods.

Maternal dermatophagy is a remarkable form of parental care and provision of nutrition but was first reported only in 2006 and has now been documented in three genera in two families. Wilkinson et al. [7] predicted the widespread occurrence of maternal dermatophagy in oviparous teresomatan caecilians, and proposed that although viviparity has evolved at least four times within caecilians [6], the feeding by fetuses on maternal oviduct lining has underlying homologies in skin-feeding, oviparous ancestors. The discovery of maternal dermatophagy in $\mathrm{H}$. squalostoma provides further support for this hypothesis.

There remain many species and genera of caecilians for which we are ignorant of even basic details of their reproductive biology. This knowledge deficit reflects lack of study, the need for dedicated fieldwork to find these mostly soil-dwelling, tropical animals, concomitantly small sample sizes for most species in scientific collections, and the general difficulty of working on soil-dwelling animals in the wild, where observations are not readily made without considerable disruption to their habitat [15]. Nonetheless, recent discoveries have added substantially to our understanding of the diversity of reproductive modes, behaviours, and 
morphologies in caecilians and demonstrate the potential for dedicated fieldwork to address the knowledge deficit.

\section{Acknowledgments}

This research was supported by grants from the Zoological Society of London's EDGE Fellowship scheme and the US Fish and Wildlife Service's Wildlife Without BordersAmphibians in Decline scheme. For help with these funding schemes and for additional support the authors thank J. Dawson, C. Lawson, H. Meredith, and M. Muir. They thank T. M. Doherty-Bone and N. L. Gonwouo for practical support in Cameroon and local people for assistance in the field. They are grateful to Danny Meirte (Royal Museum for Central Africa, Tervuren) for access to collections, and the EU Synthesys scheme for funding D. J. Gower's and M. Wilkinson's visit to Tervuren. Catharina Karlsson took data on numbers of annuli of some of the BMNH specimens. The Cameroon Ministry of Forestry and Wildlife provided research (0532/PRBS/MINFOF/SG/DFAP/SDVEF/SC) and export (0195/CO/MINFOF/SG/DFAP/SDVEF/SC) permits to T. M. Doherty-Bone.

\section{References}

[1] M. H. Wake, "The reproductive biology of caecilians: an evolutionary perspective," in Reproductive Biology of Amphibians, D. H. Taylor and S. I. Guttman, Eds., pp. 73-101, Plenum Press, New York, NY, USA, 1976.

[2] S. P. Loader, M. Wilkinson, D. J. Gower, and C. A. Msuya, "A remarkable young Scolecomorphus vittatus (Amphibia: Gymnophiona: Scolecomorphidae) from the North Pare Mountains, Tanzania," Journal of Zoology, vol. 259, no. 1, pp. 93-101, 2003.

[3] A. Kupfer, H. Müller, M. M. Antoniazzi et al., "Parental investment by skin feeding in a caecilian amphibian," Nature, vol. 440, no. 7086, pp. 926-929, 2006.

[4] H. Müller, M. Wilkinson, S. P. Loader, C. S. Wirkner, and D. J. Gower, "Morphology and function of the head in foetal and juvenile Scolecomorphus kirkii (Amphibia: Gymnophiona: Scolecomorphidae)," Biological Journal of the Linnean Society, vol. 96, no. 3, pp. 491-504, 2009.

[5] M. Wilkinson and R. A. Nussbaum, "Caecilian viviparity and amniote origins," Journal of Natural History, vol. 32, no. 9, pp. 1403-1409, 1998.

[6] D. J. Gower, V. Giri, M. S. Dharne, and Y. S. Shouche, "Frequency of independent origins of viviparity among caecilians (Gymnophiona): evidence from the first "live-bearing" Asian amphibian," Journal of Evolutionary Biology, vol. 21, no. 5, pp. 1220-1226, 2008.

[7] M. Wilkinson, A. Kupfer, R. Marques-Porto, H. Jeffkins, M. M. Antoniazzi, and C. Jared, "One hundred million years of skin feeding? Extended parental care in a Neotropical caecilian (Amphibia: Gymnophiona)," Biology Letters, vol. 4, no. 4, pp. 358-361, 2008.

[8] M. Wilkinson and R. A. Nussbaum, "Caecilian phylogeny and classification," in Reproductive Biology and Phylogeny of Gymnophiona, J.-M. Exbrayat, Ed., pp. 39-78, Science Publishers, Enfield, NH, USA, 2006.

[9] M. Wilkinson, D. S. Mauro, E. Sherratt, and D. J. Gower, "A nine-family classification of caecilians (Amphibia: Gymnophiona)," Zootaxa, no. 2874, pp. 41-64, 2011.
[10] R. G. Kamei, D. San Mauro, D. J. Gower et al., "Discovery of a new family of amphibians from Northeast India with ancient links to Africa," Proceedings of the Royal Society, vol. 279, no. 1737, pp. 2396-2401, 2012.

[11] W. Dubbin, Soils, The Natural History Museum, London, UK, 2001.

[12] M. Wilkinson, H. Müller, and D. J. Gower, "On Herpele multiplicata (Amphibia: Gymnophiona Caeciliidae)," African Journal of Herpetology, vol. 52, no. 2, pp. 119-122, 2003.

[13] R. A. Nussbaum and H. Hinkel, "Revision of East African caecilians of the genera Afrocaecilia Taylor and Boulengerula Tornier (Amphibia: Gymnophiona: Caeciliaidae)," Copeia, vol. 1994, no. 3, pp. 750-760, 1994.

[14] A. Kupfer, M. Wilkinson, D. J. Gower, H. Müller, and R. Jehle, "Care and parentage in a skin-feeding caecilian amphibian," Journal of Experimental Zoology A, vol. 309, no. 8, pp. 460-467, 2008.

[15] D. J. Gower and M. Wilkinson, "Conservation biology of caecilian amphibians," Conservation Biology, vol. 19, no. 1, pp. 45-55, 2005. 

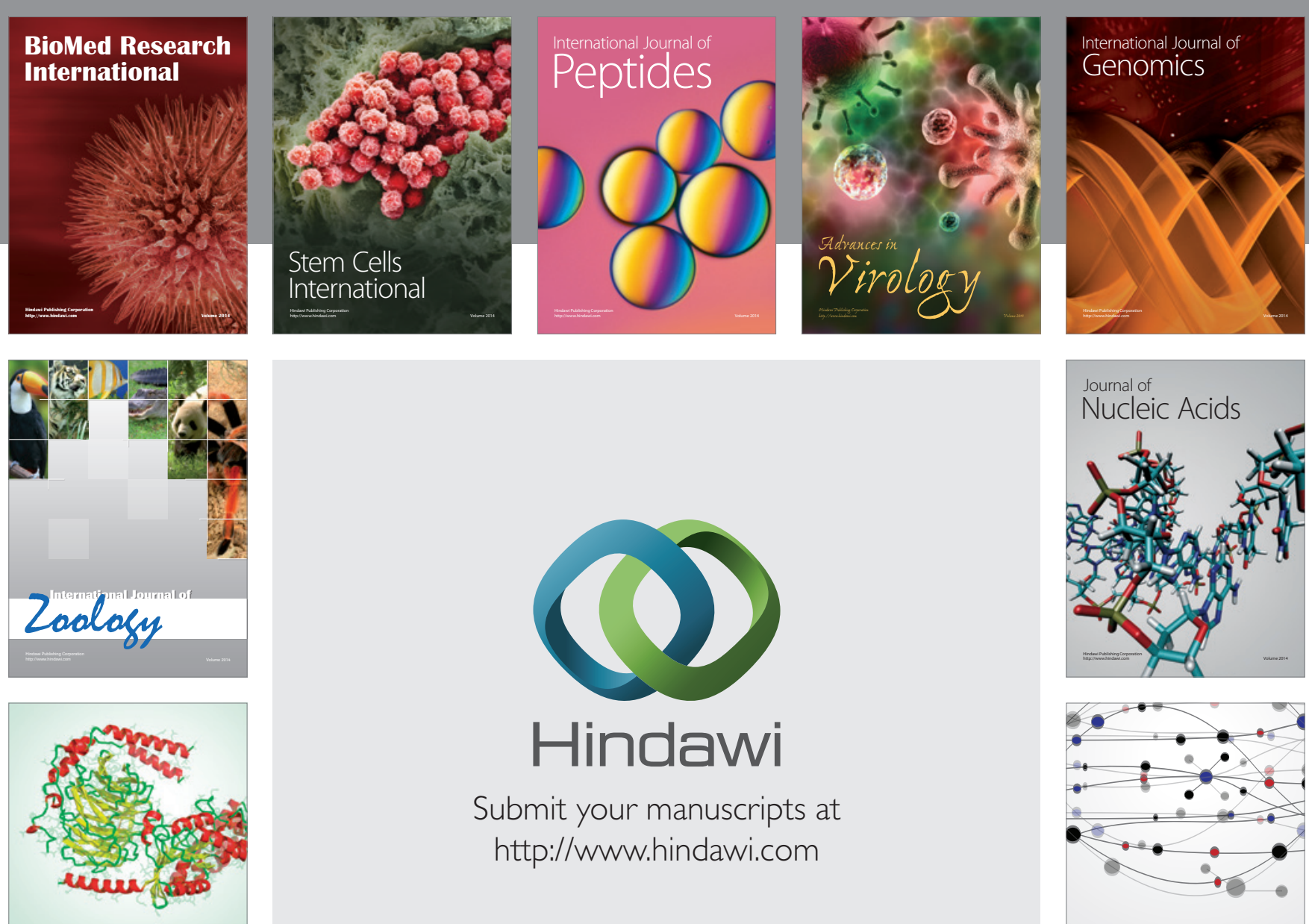

Submit your manuscripts at

http://www.hindawi.com

Signal ${ }^{\text {Jumal }}$ Transduction
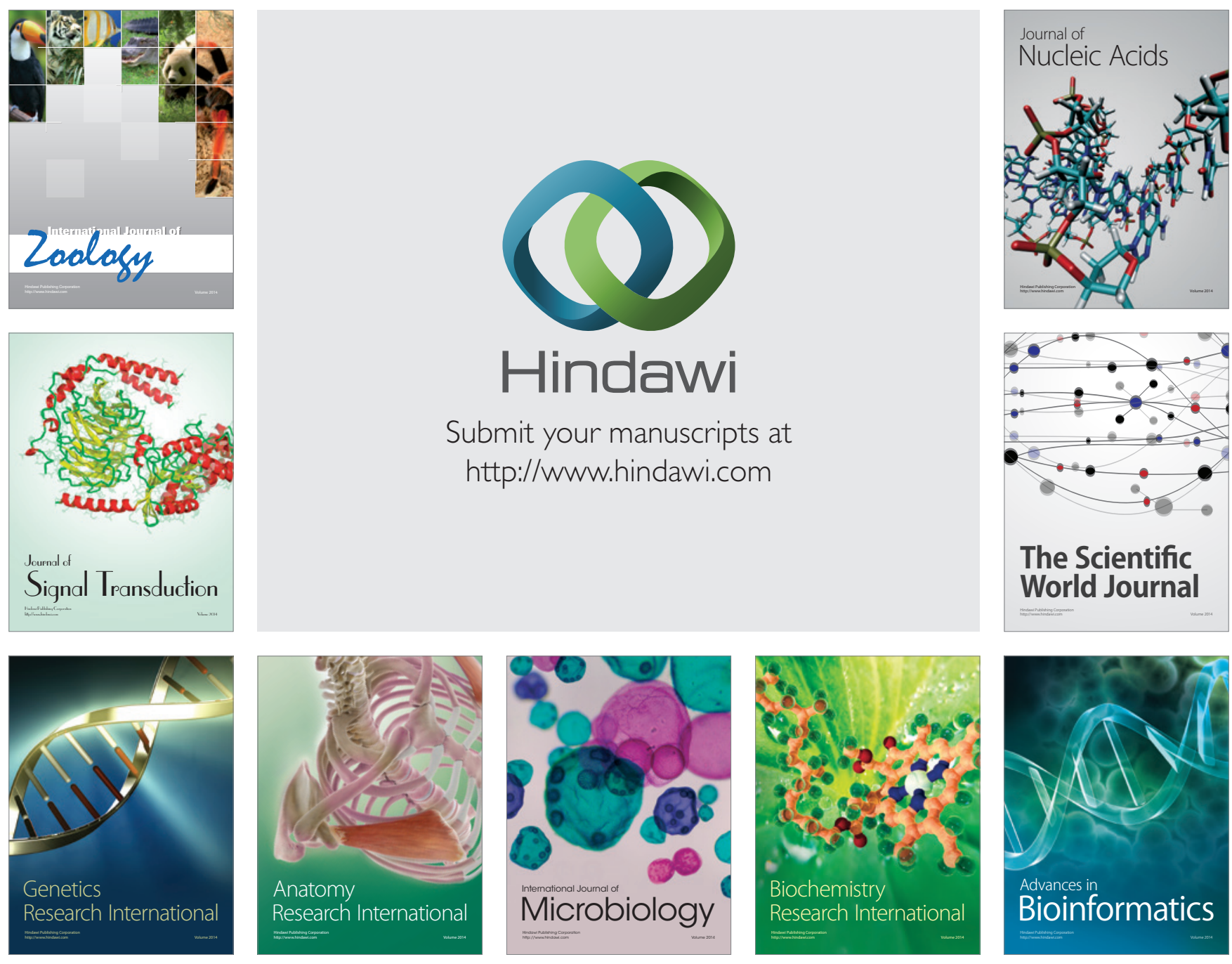

The Scientific World Journal
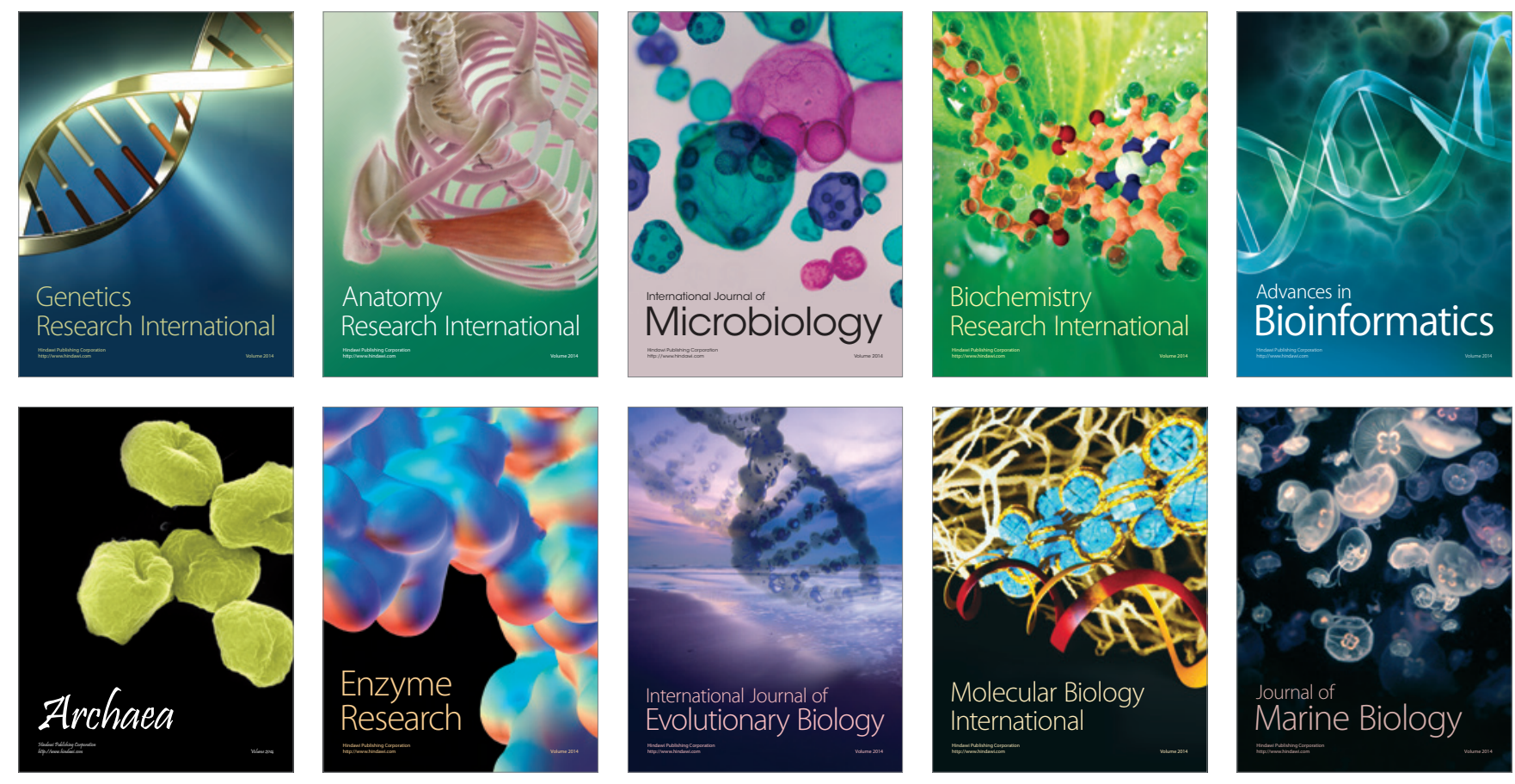